\title{
Unpredictability and chance in scientific progress
}

\author{
John Meurig THOMAS \\ University of Cambridge, England and Royal Institution of Great Britain, London
}

It is much easier to interpret the past than to predict the future, and especially so when dealing with the vicissitudes of science. The laser, for example, which did not emerge until 1960, could have been assembled decades earlier by perspicacious physicists following Einstein's classic paper in 1917 on population inversion in electronic energy levels. Equally, a widely read, mathematically-oriented engineer or computer scientist, knowing Radon's work in Leipzig, also in 1917, could have foreseen and accelerated the arrival of the technique of tomography, with all that it has done to revolutionize medicine. In this article, I cite examples of devices, techniques, procedures, and theories that exhibit a variety of different origins and subsequent development. In some instances progress had been extraordinary rapid, in others extremely slow; and in several the element of chance and coincidence has played a vital role.

With the exception of the computer itself few electronic devices have had a more profound impact on the progress of experimental science and on social interaction among human beings than the charge coupled device, otherwise known as the CCD. It has fundamentally transformed the whole of observational astronomy and very large sections of terrestrial and marine biology. The study and application of nanoscience no less than progress in nanotechnology have likewise been revolutionized by the $\mathrm{CCD}$, which is an ultrasensitive detector that picks up extremely low levels of light ranging from the infra red to the visible, the ultra violet and even X-rays. It is more than a thousand times more sensitive than the most sensitive photographic plate, which is why it is nowadays the basis of modern digital and video cameras, optical scanners and camcorders, as well as spectrometers, fax machines and other high - performance imaging facilities that are these days a part of mobile phones. (One million chil-

Received September 19, 2006.

DOI: $10.2201 / \mathrm{NiiPi} .2007 .4 .1$ dren under the age of ten in the UK alone now have a mobile phone!)

In astronomy, the CCD's use has led to sensational advances, for in the last fifteen years our knowledge of the size of the visible pageant of the heavens has increased over a thousand-fold. The CCD has also transformed gastroenterology, for in association with earlier advances in flexible fibre optics, it has brought well nigh to perfection the endoscope for examining inside the human body and, very recently, inside blood vessels. And in the so-called Census of Marine Life (COML) of a few years ago - an international project to map the biodiversity of the oceans, which are the world's most under-explored environment — it was found that the hitherto most inaccessible stretch of ocean, deep beneath the Arctic ice-cap, is teeming with far more life than scientists had ever thought possible. Numerous hitherto unidentified species, many of which are new to science, have been discovered — suspected new species of jellyfish and of squid and octopus, never seen previously, were found in those northerly waters.

At the more commercial, consumer level, the CCD has comprehensively changed our way of recording both scientific and family images. Digital camera transmission via the internet is widespread; and there has been a concomitant slump, in the manufacture of conventional cameras and films. CCDs have given a great boost to investigations of animal behaviour, because they make possible ultra-sensitivity in nightvision video recording. They also figure in the armoury of modern military warfare.

It was Willard Boyle and George Smith, working at AT. and T. Bell Laboratories in 1969, who invented the CCD. Yet - and this is the quintessential point - there was no immediate great excitement within those laboratories when the patent was duly filed. The revolutionary features of the CCD took some time to register. Immediate technical and commercial exploitation did not occur. Fairchild was the first company to manufacture 
CCDs (in 1974); but only gradually did their full potential and impact become universally apparent to all the manufacturers of electronic equipment. Moreover, it took until 2006 before the US National Academy of Engineering awarded Boyle and Smith their coveted C.S. Draper Prize for their remarkable invention.

Even slower exploitation took place in the case of fax machines. The very first was designed and patented in 1843 by Alexander Bain of Scotland, thirty three years before the telephone and Morse were used. Giovani Caselli, the Sienese physicist working in Florence, brought forth a robust, reliable fax machine (in 1861) which he called the pantélégraphe, and in the first year of its use he sent nearly 5,000 fax messages! In 1924, the RCA company in the US marketed what they called a transoceanic radio fax; and it was used to transmit a photograph of President Calvin Coolidge from New York to London in 1929. Yet when the expert Commission set up in 1937 by President Roosevelt to advise him of the most important technical and industrial development for the next thirty years or so, the fax machine was not mentioned in the final report! This is all the more surprising for in the early 1900s the American scientist Arthur Korn had invented a photo-electric scanning fax machine which, by 1910 , was used constantly to link Paris, London, and Berlin over the telephone network. I knew a chief scientific advisor to the UK Ministry of Defence in the 1960s who turned down "as surplus to needs" a fax machine that had been demonstrated to him for future military deployment. In later life he regarded it as one of his greatest errors of judgement. It was not until 1987, when the Canon Company in Japan introduced the first plain paper fax machine - at the time (purely coincidentally) of a prolonged postal (letter) delivery strike in Britain - that the fax machine became an indispensable instrument at least in the UK.

Slower exploitation still occurred in the case of the fuel cell, which was first devised by the Welsh lawyer W.R. Grove in the late 1830s. Here, however, it is largely the technical difficulties posed by electro catalysis (the phenomenon involved in converting chemical combustion directly into electrical energy) that has held up the widespread use of the fuel cell as an environmentally benign means of generating energy for transport, heating and general electrical production.

By contrast to all these examples, the chance discovery of $X$-rays by Roentgen had immediate and dramatic consequences. It was a fortunate fact, that evening on 8th November 1895, that samples of fluorescent platinocyanide compounds (in which Roentgen was interested) were lying on a table-top not far from where he was experimenting with a Crookes tube, investigating the discharge of electricity through an evacuated space. The fluorescence of the sample signified the liberation of unknown $(\mathrm{X})$ radiation. Within days, Roentgen had rendered visible (photographically by X-rays) the bones in his and his wife's hand. Within only a few months medicinal scientists as far afield as Moscow and Harvard were exploring the digestive systems of animals and photographing fetuses in pregnant women by X-rays. An enterprising Frenchman named Seguy patented as early as 1897 a machine for X-raying baggage at transport depots - the forerunner of the equipment now used for airport security.

Ever since, X-rays have played a pivotal rôle in medicine and scientific research and X-ray crystallography is now the single most effective technique for elucidating the structure of molecules, minerals and the enormous and burgeoning variety of new materials. Interestingly, a major intellectual advance was made by W.H. Bragg in 1915, when he suggested that Fourier methods for analysing X-ray patterns might hold the key to solving atomic locations in crystalline materials of arbitrary complexity. But it was not until John Kendrew in the mid 1950s demonstrated how the electronic computer could greatly accelerate the speed of structural retrieval (which he used in his Nobel prizewinning work on myoglobin) that the digital computer became a central and indispensable tool in all chemical molecular-biological investigations.

The invention of the CCD, the transistor and integrated circuit and the ever-smaller electronic chips associated with Japanese digital electronics wizardry were all products of planned intellectual endeavour, as was the emergence of the personal computer and the World Wide Web. The same is true of the labyrinthine networking and the recent dramatic development of Supercomputing Grids for scientific use epitomized by the spectacular succession in Japan of: the Information Technology Based laboratory (http://www.itbl.riken.jp) initiated in 2001; the Super Science Information Network (http://sinet.ad.jp); the BioGrid project (http://www.biogrip.jp); the VizGrid project (http://www.vizgrid.org ); and now, in 2006, the National Research Grid Initiative NAREGI (http:/www.naregi.org). The computational research environment that NAREGI engenders is expected in the next five years to be at the level of several hundred TFLOPS (tera-floating-point instructions per second). As Miura [1] has recently outlined this facility should solve types of nano-scale problems that cannot be solved by conventional theories and methodologies. It will also greatly facilitate quantum mechanical calculations on the molecules of life from proteins, to nucleic acids to polysaccharides. [2]

Reflecting on the dazzling growth of hardware and software associated with Information and Communica- 
tion Technology van Oortmerssen rightly says [3] "not only can we communicate with anybody, at any place, anytime, but also it is possible for us to communicate with devices and for machines to communicate with machines". This prompted him to speculate that a fundamental change - a discontinuity - may now be foreseen, namely the emergence of artificial or machine consciousness. The numerical facts that lead to this speculation are plausible: a human brain contains 100 billion cells, a number sufficient to bestow consciousness. Oortmerssen states that by the mid 21 st century the number of machines with some kind of intelligence connected to the internet will exceed the number of brain cells. But "will there be some kind of artificial consciousness?" This remains an imponderable, and takes us to uncharted territories.

Much more mundane are the practical issues already encountered by the managers and Paladins of information and communication technology. For example, the costs and sources of the electricity required to sustain ever-more sophisticated networks and grids are already a critical factor in many countries. It is interesting to recall that John Von Neumann, one of the founders of computer science, predicted in 1956: "a few decades hence, energy may be free, just like un-metered air". A far cry from the realities of today.

Chance favours the prepared mind, as Pasteur used to say, and Pushkin called chance "that Divine inventor". Chance was certainly instrumental in the discovery of radio astronomy by Jansky (and in the subsequent discovery forty years later in Cambridge of pulsars), of genetic fingerprinting by Jeffreys, of lithium-ion therapy for manic depressives by Cade in Australia, of the anti-cancer drug cis-platin by Rosenberg in the U.S., and of electrically conducting, plastic and flexible polymers initiated by Shirakawa's fortunate experiment at the Tokyo Institute of Technology in 1967.

Coincidences in time and place have also played a crucial role in the progress of science. Take, for example, Alec Jeffreys's invention at Leicester University of the technique of genetic fingerprinting announced in 1985. It was a fortunate but critical observation by Jeffreys that led to the technique, which requires for its prosecution the generation of billions of copies of single molecules of the genetic material DNA. There is an enzyme, known as DNA polymerase that can do this; but it was Mullis in 1983 who showed how his so-called PCR (polymer chain reaction) technique could do so most effectively, thereby greatly facilitating the process of genetic fingerprinting. Without the conjunction of Jeffreys and Mullis's work it would not be possible to accomplish the remarkable feats of genetic fingerprinting, which inter alia, have helped (i) solve crimes, settle paternity and immigration disputes; (ii) establish the basis of inherited diseases; (iii) enhanced transplantation biology and medicine; (iv) save endangered species and (v) establish human origins and migrations.

Another striking example occurred over a hundred years ago in Canada. Owing to a fortunate concatenation of circumstances, when the twenty seven year old Ernest Rutherford arrived in McGill University, Montreal he was able to carry out work of extraordinary significance for three reasons. First, McGill had at that time one of the best equipped physics laboratories in the world - thanks to the generosity of a wealthy donor named Sir William McDonald, who had kept abreast of world-wide developments in science: he wanted physics to flourish in Montreal. Second, there was a plentiful supply of radium bromide and other expensive compounds of radium in McGill. Third, and most important, a brilliant young (twenty three years old) English chemist named Frederick Soddy, who had been educated at Aberystwyth and Oxford, had also been appointed to the staff of McGill University at the same time as Rutherford. In eighteen months Rutherford and Soddy laid the foundation of natural radioactivity and propounded the theory of atomic transmutation. In so doing, they abandoned the hallowed view that atoms were immutable. (Perhaps it requires the adventurous, iconoclastic young to more readily cast aside what seems to be incontrovertible dogma!)

Pursuing the idea of the importance of bringing two remarkable individuals together, there are few superior examples than the story of Davy and Faraday. In 1812, Faraday was still serving his apprenticeship in a bookbinder's shop in London, when he was given tickets, by a kindly customer, to attend four spectacular lectures to be given by Sir Humphry Davy at the Royal Institution in London in March of that year. Davy's coruscating brilliance as a lecturer coupled with the succession of elegant experiments and well-rehearsed demonstrations carried out by him, enthralled the twenty one year old Faraday. He wrote up the lectures in detail, added illustrations, bound the set and sent them to Davy as part of his request to be considered for a post in Davy's laboratory. This is how Faraday started as a lowly assistant; but soon, under the tutelage of Davy, and through his own remarkable insights, he attained the pinnacles of scientific fame through his discovery of electromagnetic induction (which gave us the dynamo and transformer), of the laws of electrolysis and of the magnetooptic effect that bears his name, and which was to lead, in Maxwell and Faraday's hands, to a radical transformation of the intellectual fabric of physics. Newton's physics enables us to predict the motion of planets and trajectories of space vehicles: but Newton's physics helps us not one iota to understand the operation of the $\mathrm{CCD}$, the fax machine and the vast array of electronic 
and electromagnetic devices that are so much a feature of 21 st century life. The overwhelming majority of the sources of electricity used throughout the world still rely on the phenomenon of electro-magnetic induction discovered (and correctly explained) by the forty year old Faraday in 1831 !

\section{References}

[1] K. Miura, "Overview of Japanese science Grid project NAREGI", Prog. Informatics, no. 3, pp. 67-75, 2006.

[2] The exceptionally fast moving and already well established field of data mining, manipulation and deployment in the chemical sciences has prompted the remark [4] that "in the chemical and pharmaceutical industries, researchers now spend more time in digesting data than in generating them, whereas the reverse was true only a few years ago".

[3] G. van Oortmerssen, "The future-Everydoby and everything connected”, Prog. Informatics, no. 3, pp. 1-3, 2006.

[4] J. Gasteiger and T. Engel (Eds), Chemoinformatics: A Textbook, Wiley-VCH, Weinheim, 2003.

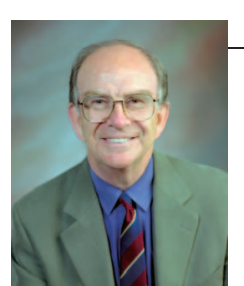

John Meurig THOMAS

John Meurig Thomas is Honorary Professor of Solid State Chemistry in the Department of Materials Science, University of Cambridge and Emeritus Professor of Chemistry and former Director (1986-91) of the Royal Institution of Great Britain, London. From 1993 to 2002 he was Master (Head) of the oldest college in Cambridge, Peterhouse, the first scientist to hold the post since it was founded in 1284. He was Head of Physical Chemistry in Cambridge (1978-86) and of Chemistry in the University College of Wales, Aberystwyth (1969-78). The recipient of numerous national and international awards for his work on materials, solid state and surface chemistry (especially catalysis), he has also served as a UK Government (Cabinet Office) Advisor, Chairman of CHEMRAWN (chemical research applied to world needs), a Trustee of the Science Museum and of the Natural History Museum, and has broadcast extensively. He was made an honorary foreign member of the Engineering Academy of Japan since1991, the year that he was knighted by Queen Elizabeth for his "services to chemistry and the popularisation of science". 